This document is a pre-print of the following published manuscript:

Jrubbs, J. B., Chapman, H., \& Shepherd, K. A. (2019). Post-traumatic stress and gambling related cognitions: Analyses in inpatient and online samples. Addictive Behaviors, 89, 128-135. https://doi.org/10.1016/j.addbeh.2018.09.035

\title{
Post-traumatic stress and gambling related cognitions: Analyses in inpatient and online samples
}

\author{
Joshua B. Grubbs, Ph.D., ${ }^{1}$ Heather Chapman, Ph.D., Kathrine A. Shepherd, Ph.D. ${ }^{2}$
}

Gambling disorder (GD) is associated with a range of psychiatric comorbidities. One comorbidity of particular interest is post-traumatic stress disorder (PTSD). Individuals with GD report much higher rates of PTSD than the general population, and individuals with this comorbidity (with both PTSD and GD) often report much greater distress and impairment in daily life in comparison to individuals with GD alone. Despite these associations, little is known about the specific ways in which PTSD and GD might influence each other. To address this gap in research, the present work sought to examine how PTSD might be related to the expression and experience of gambling related cognitions. Specifically, it was hypothesized that individuals with PTSD or symptoms of PTSD (i.e., subclinical levels of posttraumatic stress) would demonstrate greater cognitive distortions and erroneous beliefs about gambling. To test these hypotheses, we analyzed data from two samples, an inpatient sample of U.S. Armed Forces veterans seeking treatment for gambling disorder $(n=332)$ and an online sample of largely recreational gambling U.S. adults $(n=589)$. Results consistently revealed that individuals with PTSD or symptoms of PTSD were likely to report greater gambling related cognitions. These findings persisted, even when gambling symptom severity and trait neuroticism were held constant. Collectively, these results suggest that PTSD is uniquely associated with greater cognitive distortions and erroneous beliefs about gambling behaviors.

Problem and pathological gambling or Gambling Disorder (hereafter: GD) is the most extensively studied and documented behavioral addiction (Fauth-Bühler, Mann, \& Potenza, 2017; Grant, Potenza, Weinstein, \& Gorelick, 2010; Petry, 2005; Reilly \& Smith, 2013). Although debates around the exact characterization and classification of this disorder continue into the present (e.g., impulse control disorder vs. addictive disorder) (Grant et al., 2014; K. Mann, Leménager, Kiefer, \& FauthBühler, 2017; Karl Mann, Fauth-Bühler, Higuchi, Potenza, $\&$ Saunders, 2016), there is a general consensus in psychiatric and mental-health fields that GD is a legitimate and life-altering problem (Reilly \& Smith, 2013). Even so, despite the extensive body of knowledge around this disorder, GD research is still burgeoning in many areas, with research into the comorbidity of GD and symptoms of post-traumatic stress and/or post-traumatic stress disorder (PTSS/D) being a particularly notable example. Although links between these two disorders are clear (Biddle,
Hawthorne, Forbes, \& Coman, 2005; Chou \& Afifi, 2011), the ways in which they might influence each other is not. The present study was designed to specifically examine the relationships between GD and PTSS/D, with a focus on how the comorbidity of these conditions might affect gambling related cognitions.

\section{PTSS/D and Gambling}

Gambling disorder is highly comorbid with a range of psychological difficulties, including depression and anxiety (Blaszczynski \& Nower, 2002; Ciccarelli, Griffiths, Nigro, \& Cosenza, 2017; Elman, Tschibelu, \& Borsook, 2010), substance use disorders (Dowling, Merkouris, \& Lorains, 2016; Najavits, Meyer, Johnson, \& Korn, 2011; Petry, Stinson, \& Grant, 2005; Wanner, Vitaro, Carbonneau, \& Tremblay, 2009), and personality pathology (Dowling et al., 2014). In addition, rates of PTSD in individuals with GD are often substantially larger than what would be expected in the general population (e.g., 19\%, Ledgerwood \& Milosevic, 2015; 34\%,

\footnotetext{
${ }^{1}$ Department of Psychology

Bowling Green State University

${ }^{2}$ Louis Stokes Cleveland VA Medical Center
}

Declaration of Interests: None.

Correspondence concerning this article should be addressed to Joshua B. Grubbs, Ph.D., Department of Psychology, Bowling Green State University, Bowling Green, OH, 43403.

Email: GrubbsJ@BGSU.edu

Author Note: Joshua B. Grubbs, Department of Psychology, Bowling Green State University; Heather Chapman, Veterans Addiction Recovery Program, Louis Stokes Cleveland VA Medical Center; Kathrine A. Shepherd, Louis Stokes Cleveland VA Medical Center. We gratefully acknowledge the support of the National Center for Responsible Gaming in the form of a Seed Grant awarded to the first author of this manuscript. The content of this manuscript does not necessarily reflect the views of the funding agencies and reflects the views of the authors. A pre-print of this manuscript (prior to peer-review) was made available publicly on APA's preferred pre-print server, PsyArXiv. Additionally, portions of this data have been presented upon at national conferences. 
This document is a pre-print of the following published manuscript:

Jrubbs, J. B., Chapman, H., \& Shepherd, K. A. (2019). Post-traumatic stress and gambling related cognitions: Analyses in inpatient and online samples. Addictive Behaviors, 89, 128-135. https://doi.org/10.1016/j.addbeh.2018.09.035

Ledgerwood \& Petry, 2006; 41\%, Taylor \& Sharpe, 2008; 24\%, Toneatto \& Pillai, 2016; 17\%, Westermeyer, Canive, Garrard, Thuras, \& Thompson, 2005); and epidemiological studies have demonstrated that individuals with GD are often at much higher risk of comorbid PTSS/D than individuals without GD (Chou \& Afifi, 2011; Kessler et al., 2008).

Despite the clear overlap between these two disorders, the etiological pathways between them are unclear. For example, in one study, a diagnosis of PTSD at baseline was associated with increased odds of experiencing problematic gambling 10 years later (Scherrer, Slutske, et al., 2007). Similarly, other works has found that childhood trauma is associated with risk of developing GD later in life (Petry, Steinberg, \& The Women's Problem Gambling Research Group, 2005; Scherrer, Slutske, et al., 2007; Scherrer, Xian, et al., 2007). However, in a longitudinal, nationally representative study, whereas GD generally preceded the development of psychiatric comorbidities such as depression or substance use disorders, GD and PTSD were equally likely to precede one another (Parhami et al., 2014).

Regardless of etiology, it is clear that comorbid PTSD and GD are generally associated with more severe distress and impairment in daily life. Individuals with both PTSD and GD are more likely to report psychological distress, more likely to have a range of other comorbid pathologies, more likely to experience suicidal ideation, and more likely to utilize mental health treatment services (Najavits, 2010; Najavits et al., 2011). Moreover, in a study of individuals with GD in the community, individuals with both disorders were more likely to exhibit trait negative affectivity and more likely to report using gambling as a means of coping with negative affect (Ledgerwood \& Milosevic, 2015), suggesting that the GD and PTSS/D comorbidity is a particularly problematic convergence of psychopathologies. Even so, more work is needed to elucidate how this comorbidity influences the experience and expression of GD. One domain in which this comorbidity may be of particular interest is gambling related cognitions.

\section{Gambling Related Cognitions}

Within GD research, gambling related cognitions (hereafter: GRCs) are well-documented phenomena, with gambling related cognitive distortions being common. Some of these distortions are expressions of general heuristics and their corresponding biases (e.g., gambler's fallacy and the representativeness heuristic; illusory correlations and the availability heuristic; Goodie \& Fortune, 2013), whereas others seem to be specific to gambling (e.g., illusions of control; Fortune \& Goodie, 2012), or to stem from erroneous beliefs about gambling in general (e.g., gambling expectancies; Raylu \& Oei, 2004).
Regardless of the etiological nature of these beliefs, they often influence gambling behaviors.

Many studies have noted that elevated GRCs are associated with future susceptibility to gambling and greater problems with gambling (Johansson, Grant, Kim, Odlaug, \& Götestam, 2009; MacKay \& Hodgins, 2012; Yakovenko et al., 2016). Representative samples have found that GRCs are linked to problem gambling severity (Cunningham, Hodgins, \& Toneatto, 2014). Furthermore, specific gambling experiences (e.g., near-misses) are known to promote greater experiences of certain GRCs (e.g., illusions of control; Billieux, Linden, Khazaal, Zullino, \& Clark, 2012; Clark, Lawrence, Astley-Jones, \& Gray, 2009). In sum, there is now clear evidence that individuals with more severe expressions of problem gambling or GD are also likely to experience more severe GRCs, and that gambling experiences and GRCs likely form reciprocal relationships, with each being related to greater experience of the other.

A number of studies have also linked GRCs to psychological distress more broadly. For example, in early work on GRCs, positive associations were generally observed between psychopathology and gambling related cognitive fallacies (Po Oei, Lin, \& Raylu, 2008; Raylu \& Oei, 2004), and depression and negative affectivity were consistently related to higher levels of GRCs (Barrault \& Varescon, 2013; Young \& Wohl, 2009). Similarly, there are also clear links between specific GRCs (e.g., gambling related positive expectancies) and greater psychological distress in the form of depression and anxiety (Ciccarelli et al., 2017). These associations also seem to appear in a variety of cultural contexts, with studies of gamblers in Italy demonstrating links between GRCs and a variety of distress indicators such as anxiety, depression, and neuroticism (Iliceto et al., 2015). Similarly, in a Turkish sample, such cognitions were associated with greater negative affect (Arcan \& Karanci, 2015). Collectively, these findings suggest that GRCs are associated with greater psychological distress, though it is unclear which direction these associations might flow (e.g., which phenomena leads to the other) or if both phenomena might be better accounted for by underlying variables such as neuroticism (i.e., a dispositional tendency toward negative affect).

Beyond general distress, there is evidence that GRCs also influence treatment for gambling disorder. For example, GRCs are generally associated with a lower likelihood of treatment completion, while individuals who successfully complete treatment for GD seem to display reductions in such distortions (Smith et al., 2010).

Furthermore, individuals experiencing greater levels of GRCs are more likely to relapse after periods of abstinence (Oei \& Gordon, 2008). Even so, despite clear associations 
This document is a pre-print of the following published manuscript:

Jrubbs, J. B., Chapman, H., \& Shepherd, K. A. (2019). Post-traumatic stress and gambling related cognitions: Analyses in inpatient and online samples. Addictive Behaviors, 89, 128-135. https://doi.org/10.1016/j.addbeh.2018.09.035

between GRCs and GD, there is little evidence that targeting such distortions in treatment provides clinically significant benefit (Toneatto \& Gunaratne, 2009), although cognitive behavior therapy more generally is often effective in treating GD (Fortune \& Goodie, 2012). In short, although GRCs are associated with greater gambling severity, greater susceptibility to future gambling behaviors, reduced treatment adherence, and greater risk of gambling relapse, there is still mixed evidence regarding the clinical utility of specifically addressing such distortions. Additionally, there is very little research examining how such distortions might interact with or be influenced by other psychological disorders, despite clear links between such cognitions and greater

psychopathology. This final point is especially true of the links between GRCs and PTSS/D.

\section{The Present Study}

Given established links between GRCs and psychological distress and between PTSD and GD, it is reasonable to conclude that PTSD symptoms in gambling populations may be associated with greater GRCs. Given the particularly high rates of distress experienced by individuals with both PTSD and GD, understanding how these two disorders might interact is particularly relevant. However, at present, there does not seem to be any research directly linking symptoms of post-traumatic stress to gambling related cognitions. Building on this need, the purpose of the present study was to examine links between PTSD and increased GRCs among gamblers. Additionally, given the known associations between dispositional negative affect (i.e., trait neuroticism) and symptoms of post-traumatic stress (Kotov, Gamez, Schmidt, \& Watson, 2010), problematic gambling behaviors (Bagby et al., 2007), and gambling-related cognitions (Iliceto et al., 2015), it is important to establish links between posttraumatic stress and gambling related cognitions, above and beyond trait neuroticism,

Based on these foundations, we posited the following questions.

1) Do gamblers with PTSD demonstrate greater levels of GRCs, relative to their peers without PTSD?

2) Are symptoms of post-traumatic stress linked to greater GRCs (i.e., including the full spectrum of PTSD symptoms, rather than just those that meet criteria for PTSD)?

3) Do links between post-traumatic stress symptoms and gambling related cognitions persist, when statistically controlling relevant covariates (e.g., trait neuroticism and gambling symptom severity)?

In sum, we predicted that gamblers with symptoms of post-traumatic stress or a confirmed diagnosis of PTSD would demonstrate higher levels of GRCs, and these findings would persist, even when trait neuroticism and gambling symptom severity were held constant.

\section{Participants and Procedure}

For Sample 1, we analyzed intake assessment data from veterans of the U.S. Armed Forces that were in residential treatment for Gambling Disorder $(N=332,80 \%$ men, $\left.M_{\text {age }}=53.5, S D=11.5\right)$. Given that the program was a residential treatment program for GD, all participants had a diagnosis of GD prior to entry into the program. Participants identified primarily as White/Caucasian (69\%), followed by African-American/Black (21\%), Native American/American Indian (3\%), Asian/Pacific Islander (3\%), Hispanic/Latino (2\%), and other (2\%).

In Sample 2, we recruited adults $(N=1,137)$ via Amazon's Mechanical Turk (MTurk) online labor marketplace via the TurkPrime data acquisition platform (Litman, Robinson, \& Abberbock, 2017). Given the focus of the study, only participants who endorsed any sort of gambling in the past 12 months were included (inclusion rate $=77 \% ; N=881)$. Participants were screened into the study via an affirmative response to the question: "In the past year, have you ever gambled? This includes any of the following: purchasing scratch-offs, purchasing lottery tickets, playing the stock market, betting on sports, going to casinos, playing keno, playing slots or video poker, playing games for money, or playing fantasy sports for money."

Among participants who were screened into the overall study, only those who indicated a history of trauma experience or exposure (see inclusion criteria below) were included in analyses. Our final sample size was 589 (inclusion rate $=86 \%$; 43\% men, $M_{\text {age }}=36.1, S D=11.0$ ). Of note, MTurk is used extensively in social science research (Buhrmester, Kwang, \& Gosling, 2011) and is useful for studying clinically relevant phenomena (Chandler \& Shapiro, 2016; Shapiro, Chandler, \& Mueller, 2013). Furthermore, this source of data is specifically useful for data on GD behaviors (Kim \& Hodgins, 2017). Participants identified primarily as White/Caucasian (76\%), followed by African-American/Black (11\%), Native American/American Indian (2\%), Asian/Pacific Islander (9\%), Hispanic/Latino (8\%), and other/prefer-notto-say $(2 \%)$.

\section{Measures}

Gambling severity. In both samples, we included the South Oaks Gambling Screen (Lesieur \& Blume, 1987) as a measure of gambling symptom severity. This measure contains 21 items and requires participants to respond to a variety of prompts such as, "Did you ever gambling more than you intended to?" or "When you gambling, how often do you go back another day to win back money you have lost?". Responses consistent with GD are assigned a value 
Irubbs, J. B., Chapman, H., \& Shepherd, K. A. (2019). Post-traumatic stress and gambling related cognitions: Analyses in inpatient and online samples. Addictive Behaviors, 89, 128-135. https://doi.org/10.1016/j.addbeh.2018.09.035

of 1; responses inconsistent with GD are assigned a value of 0 . Responses are summed.

Gambling related cognitions. We included the Gambling Related Cognitions Scale (Raylu \& Oei, 2004). This 23-item scale requires participants to respond on a scale of 1 (strongly disagree) to 7 (strongly agree) to prompts representing four possible types of gambling related cognitions: Gambling Expectancies (4 items, e.g., "Gambling makes me happier" or "Gambling makes things seem better."), Illusions of Control (4 items, e.g., "Specific numbers and colors can help increase my chances of winning," and "I have specific rituals and behaviors that increase my chances of winning"), Predictive Control (6 items, e.g., "A series of losses will provide me with a learning experience that will help me win later," and "I have some control over predicting my gambling wins"), Inability to Stop Gambling (5 items, e.g., "My desire to gambling is so overpowering," and "I will never be able to stop gambling"), and Interpretative Bias (4 items, e.g., "Relating my winnings to my skill and ability makes me continue gambling," and "Remembering how much money I won last time makes me continue gambling"). For the present work, responses on each subscale were averaged.

Posttraumatic stress/PTSD. In Sample 1, PTSS/D was assessed via the presence $(n=140)$ or absence $(n=189)$ of a PTSD diagnosis on the veteran's medical record. This diagnosis was based upon medical history, chart review, and clinical interviews with patients. In short, upon entry into the treatment program, previous diagnoses of PTSD were noted. Subsequent to this notation, patient health records, current symptoms, and previous diagnostic history were independently reviewed by a staff psychologist and a staff psychiatrist. When both staff members were in agreement that the pre-existing diagnosis of PTSD was currently accurate (e.g., symptoms of PTSD were still met), the presence of this diagnosis was recorded.

In Sample 2, post-traumatic stress was assessed via two methods. First, participants completed the Life Events Checklist (Gray, Litz, Hsu, \& Lombardo, 2004). This measure assesses experiences with (e.g., "it happened to you personally," "you witnessed it happen to somebody else," or "you learned about it happening to a close family member or close friend") with 17 different types of traumatic events (e.g., "fire or explosion," "combat or exposure to a war-zone (in the military or as a civilian)"). For the purpose of the present work, we only included respondents who had first-hand experience with such traumas (e.g., directly experienced or witnessed occurring). In our sample, consistent with national prevalence rates (e.g., 89\%, Kilpatrick et al., 2013), 85.6\% of participants $(n=589)$ reported either directly experiencing or personally witnessing one of the specified traumatic events.
For participants who endorsed the experience of a traumatic event, we administered the PTSD ChecklistCivilian version (PCL-C; Ruggiero, Ben, Scotti, \& Rabalais, 2003). Among those included $(n=589)$, participants were directed to think of the single most traumatic event they had experienced in their lifetimes, and, with that trauma in mind, they were directed to "indicate how much you have been bothered by" each of 17 items "in the last month." Items include "Repeated, disturbing, memories, thoughts, or images of a stressful experience from the past" and "Avoid thinking about or talking about a stressful experience from the past or avoid having feelings related to it." Participants responded using a scale of 1 (not at all) to 5 (extremely). Responses were summed.

Neuroticism. In Sample 1, we measured neuroticism using the neuroticism subscale of the Revised NEO Personality Inventory (NEO-PI-R; Costa \& MacCrae, 1992). For our analyses, all subscales of Neuroticism (Anxiety, Angry Hostility, Depression, SelfConsciousness, Immoderation, Vulnerability) were included as controls.

In Sample 2, we assessed neuroticism using the International Personality Inventory Pool NEO 120, which is functionally almost identical to the NEO-PI-R (IPIPNEO-120; Maples, Guan, Carter, \& Miller, 2014). We included all six subscales of the neuroticism facet as control variables (Anxiety, Anger, Depression, SelfConsciousness, Immoderation, Vulnerability).

\section{Analytic Plan}

To test our hypotheses, we conducted a series of analyses. For both samples, descriptive statistics, including measures of central tendency, skew, and scale reliability were computed. These values are available in Table 1. Additionally, for Sample 1, we computed independent sample t-tests for all gambling related cognitions between those who did and those who did not have PTSD. These results are available in Table 2. For both samples, we computed Pearson correlations with Holm-adjusted test statistics between all key variables (e.g., posttraumatic stress, gambling related cognitions, and gambling symptom severity). These results are available in Table 3. Finally, for both samples we conducted a series of two-step, Hierarchical regressions for each gambling related cognition. To determine the unique influence of posttraumatic stress on such cognitions, above and beyond control variables (gambling symptom severity and neuroticism), we entered gambling symptom severity and neuroticism subscale scores into the first step of each regression, and in the second step, we entered posttraumatic stress.

These results are available in Tables 4 (Sample 1) and 5 (Sample 2) respectively. 
This document is a pre-print of the following published manuscript:

Jrubbs, J. B., Chapman, H., \& Shepherd, K. A. (2019). Post-traumatic stress and gambling related cognitions: Analyses in inpatient and online samples. Addictive Behaviors, 89, 128-135. https://doi.org/10.1016/j.addbeh.2018.09.035

\section{Results}

Independent t-tests in Sample 1 revealed no significant differences between those with PTSD and those without with regards to severity of gambling symptoms. However, there were significant differences for all five gambling related cognitions, wherein respondents with PTSD scored significantly higher on all reported higher levels of each cognition (See Table 1). These effects were consistently in the small-to-moderate range (Cohen's $d=$ .25-.44).

Subsequent correlations in both samples revealed significant (at alpha $=.05$ ) positive correlations between post-traumatic stress and all five gambling related cognitions (See Table 2). Again, these effect sizes were consistently in the small to moderate range $(r=.125-.246)$. We further noted, in Sample 2, that the correlations between gambling symptom severity (as measured by the SOGS) were quite strong ( $r=.432-.596)$.

Finally, results from two-step, hierarchical regression analyses demonstrated that post-traumatic stress was consistently significantly related to gambling related cognitions above and beyond gambling severity and neuroticism. However, in both samples, the unique variance accounted for in such cognitions, above and beyond gambling symptom severity and neuroticism, was relatively small $\left(\Delta R^{2}=.004-.037\right)$.

\section{Discussion}

At the outset of this work, we sought to test specific hypotheses concerning the relationship of posttraumatic stress to GRCs. Below, we summarize our findings and discuss the implications of our work.

\section{Gambling and Post Traumatic Stress}

Consistent with a growing body of literature on the topic, we observed links between gambling behaviors, problematic gambling, and PTSS/D. In our first sample, for which all participants had confirmed diagnoses of GD, there were no significant differences in gambling symptoms between individuals with and without a diagnosis of PTSD. Given that this sample displayed extreme levels of problematic gambling behaviors (e.g., positively skewed variable; evidenced by seeking treatment in a residential program specialized in GD), such a lack of differences is likely a function of the sample, rather than a true lack of a relationship between the two disorders. Moreover, in our community sample of internet-using adults who also gambled, there were clear, positive, and moderately sized links between PTSD and gambling symptom severity. Collectively, these findings add to the body of literature documenting links between posttraumatic stress and problematic gambling behaviors.

Moving further, we sought to explicitly test the hypothesis that post-traumatic stress would be related to greater levels of GRCs, as PTSD is associated with a variety of cognitive distortions (Cox, Resnick, \& Kilpatrick, 2014). In both samples, we found consistent support for this hypothesis, though our effect sizes were most often in the small-to-moderate range. Specifically, in our sample of inpatient veterans, comparisons between those who had PTSD and those who did not consistently revealed that those with PTSD had higher levels of all specific gambling related cognitions, as well as overall gambling related cognitions. Similarly, in both samples, cross-sectional correlations revealed small-to-moderate positive associations between PTSD and all gambling related cognitions.

Despite the size of associations found, recent metaanalytic studies of correlation coefficients in psychological research suggest that the findings of the present study are on par with published research in applied psychological domains (Bosco, Aguinis, Singh, Field, \& Pierce, 2015) and consistent with prior literature linking various mental health concerns to gambling related cognitions (Po Oei et al., 2008; Raylu \& Oei, 2004; Young \& Wohl, 2009). Moreover, the associations between post-traumatic stress and gambling related cognitions does not seem to simply be a function of psychological distress more generally, as the association persisted in both samples, even when the component facets of trait neuroticism were held constant. These links also persevered when gambling symptom severity was held constant statistically. In sum, even when problematic gambling severity and dispositional tendencies toward negative affect were both held constant, posttraumatic stress demonstrated clear relationships with gambling related cognitions. Collectively, these findings suggest there is a unique and meaningful relationship between PTSD and GRCs.

\section{Implications}

To our knowledge, this study is the first empirical examination of relationships between post-traumatic stress and GRCs. Given the abundantly clear links between these two disorders, understanding the nuanced ways in which the two are related may bear very clear implications for both research and treatment. Specifically, as has been previously documented (Ledgerwood \& Milosevic, 2015; Najavits, 2010, 2011; Najavits et al., 2011), individuals with both GD and symptoms of post-traumatic stress often experience a broader range of comorbidities, greater severity of problem gambling behaviors, differing motivations for gambling, and generally more distress compared to those with GD alone. In short, individuals who are experiencing both post-traumatic stress and GD are likely to both be in greater need of mental health services and be more complex and difficult to treat. The findings of the present study may shed light on one potential treatment avenue for such complex cases. 
This document is a pre-print of the following published manuscript:

Jrubbs, J. B., Chapman, H., \& Shepherd, K. A. (2019). Post-traumatic stress and gambling related cognitions: Analyses in inpatient and online samples. Addictive Behaviors, 89, 128-135. https://doi.org/10.1016/j.addbeh.2018.09.035

Much prior research has established that gambling related cognitions are related to severity of problematic gambling behaviors and treatment outcomes among those seeking to reduce problematic gambling behaviors.

Although the general treatment of GRCs has not yet proven to be a fruitful primary target of therapy for GD, future work should examine whether such cognitions are useful targets of treatment for people with both disorders, particularly in light of the present study indicating that individuals with symptoms of post-traumatic stress are more prone to gambling related cognitions.

Finally, although our work is not causal in nature, it does raise the possibility that post-traumatic stress might affect how individuals think about and interpret gambling related experiences (i.e., that post-traumatic stress might increase the likelihood of developing GRCs). Future longitudinal work is likely needed to explore these links more fully, but, given that post-traumatic stress is known to increase the odds of later developing GD, it is plausible that one mechanism for this increased risk are increased GRCs.

\section{Limitations}

Despite the consistency of our findings, we do acknowledge a few very clear methodological limitations that should be considered. Chief among these limitations is the fact that our findings are cross-sectional. Causality is not implied and should not be inferred from our findings. Although there are clear and consistent relationships between post-traumatic stress and gambling related cognitions, the directionality of these associations is speculative until these hypothesized relationships are explored using longitudinal or experimental designs. Additionally, we relied exclusively on self-report data, which is known to be limited (Chan, 2009). The extremely divergent measures of post-traumatic stress are also a point of concern, as our clinical sample relied on a dichotomous indicator rather than scale data. Finally, the overall generalizability of our findings is yet unclear, despite the consistency of findings. Both samples were rather specialized (e.g., veterans in inpatient treatment vs. largely recreational gamblers recruited online). Future work should examine these relationships in non-veteran samples of individuals with GD, as well as among gamblers that display higher risk factors, while still falling short of GD.

\section{Conclusions}

Prior research has consistently shown that gambling disorder and post-traumatic stress disorder are often comorbid and that their comorbidity is often a source of profound psychological distress. The present work sought to illuminate the specific relationships between these disorders, with a specific focus on the role that such comorbidity may play in influencing gambling related cognitions. Using both clinical and community samples, we found consistent evidence for the prediction that symptoms of PTSD are associated with more erroneous beliefs about and cognitive distortions regarding gambling behaviors. Importantly, these findings were evident even at sub-clinical levels of both disorders (e.g., in community members with symptoms of both disorders that fell below clinical diagnostic cut off points). Collectively, our findings provide further evidence for the idea that the comorbidity of PTSD and GD is a particularly problematic convergence of psychopathologies while also highlighting potential mechanisms by which this comorbidity may occur.

\section{References}

Arcan, K., \& Karanci, A. N. (2015). Adaptation Study of the Turkish Version of the Gambling-Related Cognitions Scale (GRCS-T). Journal of Gambling Studies, 31, 211-224. https://doi.org/10.1007/s10899-013-9414-5

Bagby, R. M., Vachon, D. D., Bulmash, E. L., Toneatto, T., Quilty, L. C., \& Costa, P. T. (2007).

Pathological gambling and the five-factor model of personality. Personality and Individual

Differences, 43, 873-880.

https://doi.org/10.1016/j.paid.2007.02.011

Barrault, S., \& Varescon, I. (2013). Cognitive Distortions, Anxiety, and Depression Among Regular and Pathological Gambling Online Poker Players. Cyberpsychology, Behavior, and Social Networking, 16, 183-188. https://doi.org/10.1089/cyber.2012.0150

Biddle, D., Hawthorne, G., Forbes, D., \& Coman, G. (2005). Problem gambling in Australian PTSD treatment-seeking veterans. Journal of Traumatic Stress, 18, 759-767. https://doi.org/10.1002/jts.20084

Billieux, J., Linden, M. V. der, Khazaal, Y., Zullino, D., \& Clark, L. (2012). Trait gambling cognitions predict near-miss experiences and persistence in laboratory slot machine gambling. British Journal of Psychology, 103, 412-427.

https://doi.org/10.1111/j.2044-8295.2011.02083.x

Blaszczynski, A., \& Nower, L. (2002). A pathways model of problem and pathological gambling. Addiction, 97, 487-499.

Bosco, F. A., Aguinis, H., Singh, K., Field, J. G., \& Pierce, C. A. (2015). Correlational effect size benchmarks. Journal of Applied Psychology, 100, 431-449. https://doi.org/10.1037/a0038047

Buhrmester, M., Kwang, T., \& Gosling, S. D. (2011). Amazon's Mechanical Turk: A new source of inexpensive, yet high-quality, data? Perspectives on Psychological Science, 6, 3-5. 
This document is a pre-print of the following published manuscript:

Jrubbs, J. B., Chapman, H., \& Shepherd, K. A. (2019). Post-traumatic stress and gambling related cognitions: Analyses in inpatient and online samples. Addictive Behaviors, 89, 128-135. https://doi.org/10.1016/j.addbeh.2018.09.035

Chan, D. (2009). So why ask me? Are self-report data really that bad. Statistical and Methodological Myths and Urban Legends: Doctrine, Verity and Fable in the Organizational and Social Sciences, 309-336.

Chandler, J., \& Shapiro, D. (2016). Conducting clinical research using crowdsourced convenience samples. Annual Review of Clinical Psychology, 12, 53-81. https://doi.org/10.1146/annurev-clinpsy-021815093623

Chou, K.-L., \& Afifi, T. O. (2011). Disordered (pathologic or problem) gambling and axis i psychiatric disorders: Results from the national epidemiologic survey on alcohol and related conditions. American Journal of Epidemiology, 173, 1289-1297. https://doi.org/10.1093/aje/kwr017

Ciccarelli, M., Griffiths, M. D., Nigro, G., \& Cosenza, M. (2017). Decision making, cognitive distortions and emotional distress: A comparison between pathological gamblers and healthy controls. Journal of Behavior Therapy and Experimental Psychiatry, 54, 204-210. https://doi.org/10.1016/j.jbtep.2016.08.012

Clark, L., Lawrence, A. J., Astley-Jones, F., \& Gray, N. (2009). Gambling Near-Misses Enhance Motivation to Gamble and Recruit Win-Related Brain Circuitry. Neuron, 61, 481-490. https://doi.org/10.1016/j.neuron.2008.12.031

Costa, P. T., \& MacCrae, R. R. (1992). Revised NEO personality inventory (NEO PI-R) and NEO fivefactor inventory (NEO-FFI): Professional manual. Psychological Assessment Resources, Incorporated.

Cox, K. S., Resnick, H. S., \& Kilpatrick, D. G. (2014). Prevalence and correlates of posttrauma distorted beliefs: Evaluating DSM-5 PTSD expanded cognitive symptoms in a national sample. Journal of Traumatic Stress, 27, 299-306.

Cunningham, J. A., Hodgins, D. C., \& Toneatto, T. (2014). Relating severity of gambling to cognitive distortions in a representative sample of problem gamblers. Journal of Gambling Issues, 0, 1-6. https://doi.org/10.4309/jgi.2014.29.2

Dowling, N. A., Cowlishaw, S., Jackson, A. C., Merkouris, S. S., Francis, K. L., \& Christensen, D. R. (2014). The prevalence of comorbid personality disorders in treatment-seeking problem gamblers: A systematic review and meta-analysis. Journal of Personality Disorders, 29, 735-754. https://doi.org/10.1521/pedi_2014_28_168

Dowling, N. A., Merkouris, S. S., \& Lorains, F. K. (2016). Interventions for comorbid problem gambling and psychiatric disorders: Advancing a developing field of research. Addictive Behaviors, 58, 21-30. https://doi.org/10.1016/j.addbeh.2016.02.012

Elman, I., Tschibelu, E., \& Borsook, D. (2010). Psychosocial stress and its relationship to gambling urges in individuals with pathological gambling: Stress and gambling. American Journal on Addictions, no-no. https://doi.org/10.1111/j.15210391.2010.00055.X

Fauth-Bühler, M., Mann, K., \& Potenza, M. N. (2017). Pathological gambling: a review of the neurobiological evidence relevant for its classification as an addictive disorder. Addiction Biology, 22, 885-897.

Fortune, E. E., \& Goodie, A. S. (2012). Cognitive distortions as a component and treatment focus of pathological gambling: A review. Psychology of Addictive Behaviors, 26, 298-310. https://doi.org/10.1037/a0026422

Goodie, A. S., \& Fortune, E. E. (2013). Measuring cognitive distortions in pathological gambling: Review and meta-analyses. Psychology of Addictive Behaviors, 27, 730-743. https://doi.org/10.1037/a0031892

Grant, J. E., Atmaca, M., Fineberg, N. A., Fontenelle, L. F., Matsunaga, H., Janardhan Reddy, Y. C., ... Stein, D. J. (2014). Impulse control disorders and "behavioural addictions" in the ICD-11. World Psychiatry, 13, 125-127. https://doi.org/10.1002/wps.20115

Grant, J. E., Potenza, M. N., Weinstein, A., \& Gorelick, D. A. (2010). Introduction to behavioral addictions. The American Journal of Drug and Alcohol Abuse, 36, 233-241. https://doi.org/10.3109/00952990.2010.491884

Gray, M. J., Litz, B. T., Hsu, J. L., \& Lombardo, T. W. (2004). Psychometric properties of the Life Events Checklist. Assessment, 11, 330-341. https://doi.org/10.1177/1073191104269954

Grubbs, J., Chapman, H., Milner, L., Gutierrez, I., \& Bradley, D. F. (2018). Examining links between post-traumatic stress and gambling motives: The role of positive gambling expectancies. PsyArXiv. https://doi.org/10.17605/OSF.IO/ZXW6D

Iliceto, P., Fino, E., Cammarota, C., Giovani, E., Petrucci, F., Desimoni, M., ... Oei, T. P. (2015). Factor Structure and Psychometric Properties of the Italian Version of the Gambling Related Cognitions Scale (GRCS-I). Journal of Gambling Studies, 31, 225-242.

https://doi.org/10.1007/s10899-013-9405-6

Johansson, A., Grant, J. E., Kim, S. W., Odlaug, B. L., \& Götestam, K. G. (2009). Risk Factors for Problematic Gambling: A Critical Literature 
This document is a pre-print of the following published manuscript:

Jrubbs, J. B., Chapman, H., \& Shepherd, K. A. (2019). Post-traumatic stress and gambling related cognitions: Analyses in inpatient and online samples. Addictive Behaviors, 89, 128-135. https://doi.org/10.1016/j.addbeh.2018.09.035

Review. Journal of Gambling Studies, 25, 67-92. https://doi.org/10.1007/s10899-008-9088-6

Kessler, R. C., Hwang, I., LaBrie, R., Petukhova, M., Sampson, N. A., Winters, K. C., \& Shaffer, H. J. (2008). DSM-IV pathological gambling in the National Comorbidity Survey Replication. Psychological Medicine, 38. https://doi.org/10.1017/S0033291708002900

Kilpatrick, D. G., Resnick, H. S., Milanak, M. E., Miller, M. W., Keyes, K. M., \& Friedman, M. J. (2013). National Estimates of Exposure to Traumatic Events and PTSD Prevalence Using DSM-IV and DSM-5 Criteria. Journal of Traumatic Stress, 26, 537-547. https://doi.org/10.1002/jts.21848

Kim, H. S., \& Hodgins, D. C. (2017). Reliability and validity of data obtained from alcohol, cannabis, and gambling populations on Amazon's Mechanical Turk. Psychology of Addictive Behaviors, 31, 85-94. https://doi.org/10.1037/adb0000219

Kotov, R., Gamez, W., Schmidt, F., \& Watson, D. (2010). Linking "big" personality traits to anxiety, depressive, and substance use disorders: A metaanalysis. Psychological Bulletin, 136, 768-821. https://doi.org/10.1037/a0020327

Ledgerwood, D. M., \& Milosevic, A. (2015). Clinical and personality characteristics associated with post traumatic stress disorder in problem and pathological gamblers recruited from the community. Journal of Gambling Studies, 31, 501512.

Ledgerwood, D. M., \& Petry, N. M. (2006). Posttraumatic stress disorder symptoms in treatment-seeking pathological gamblers. Journal of Traumatic Stress, 19, 411-416. https://doi.org/10.1002/jts.20123

Lesieur, H. R., \& Blume, S. B. (1987). The South Oaks Gambling Screen (SOGS): A new instrument for the identification of pathological gamblers. American Journal of Psychiatry, 144.

Litman, L., Robinson, J., \& Abberbock, T. (2017). TurkPrime.com: A versatile crowdsourcing data acquisition platform for the behavioral sciences. Behavior Research Methods, 49, 433-442. https://doi.org/10.3758/s13428-016-0727-z

MacKay, T.-L., \& Hodgins, D. C. (2012). Cognitive distortions as a problem gambling risk factor in Internet gambling. International Gambling Studies, 12, 163-175. https://doi.org/10.1080/14459795.2011.648652

Mann, K., Leménager, T., Kiefer, F., \& Fauth-Bühler, M. (2017). Pathological gambling, impulse control disorder or behavioural addiction: What do the data indicate? European Psychiatry, 41, S25-S26. https://doi.org/10.1016/j.eurpsy.2017.01.134

Mann, Karl, Fauth-Bühler, M., Higuchi, S., Potenza, M. N., \& Saunders, J. B. (2016). Pathological gambling: a behavioral addiction. World Psychiatry, 15, 297298. https://doi.org/10.1002/wps.20373

Maples, J. L., Guan, L., Carter, N. T., \& Miller, J. D. (2014). A test of the International Personality Item Pool representation of the Revised NEO Personality Inventory and development of a 120item IPIP-based measure of the five-factor model. Psychological Assessment, 26, 1070.

Najavits, L. M. (2010). Treatment utilization of pathological gamblers with and without PTSD. Journal of Gambling Studies, 26, 583-592. https://doi.org/10.1007/s10899-010-9179-z

Najavits, L. M. (2011). Treatments for PTSD and pathological gambling: What do patients want? Journal of Gambling Studies, 27, 229-241. https://doi.org/10.1007/s10899-010-9198-9

Najavits, L. M., Meyer, T., Johnson, K. M., \& Korn, D. (2011). Pathological gambling and posttraumatic stress disorder: A study of the co-morbidity versus each alone. Journal of Gambling Studies, 27, 663683. https://doi.org/10.1007/s10899-010-9230-0

Oei, T. P. S., \& Gordon, L. M. (2008). Psychosocial factors related to gambling abstinence and relapse in members of Gamblers Anonymous. Journal of Gambling Studies, 24, 91-105. https://doi.org/10.1007/s10899-007-9071-7

Parhami, I., Mojtabai, R., Rosenthal, R. J., Afifi, T. O., \& Fong, T. W. (2014). Gambling and the onset of comorbid mental disorders: A longitudinal study evaluating severity and specific symptoms. Journal of Psychiatric Practice ${ }^{\circledR}, 20,207$. https://doi.org/10.1097/01.pra.0000450320.98988. $7 \mathrm{c}$

Petry, N. M. (2005). Pathological gambling: Etiology, comorbidity, and treatment. Pathological Gambling: Etiology, Comorbidity, and Treatment., x, 417-x, 417. https://doi.org/10.1037/10894-000

Petry, N. M., Steinberg, K. L., \& The Women's Problem Gambling Research Group. (2005). Childhood Maltreatment in Male and Female TreatmentSeeking Pathological Gamblers. Psychology of Addictive Behaviors, 19, 226-229. https://doi.org/10.1037/0893-164X.19.2.226

Petry, N. M., Stinson, F. S., \& Grant, B. F. (2005). Comorbidity of DSM-IV Pathological Gambling and Other Psychiatric Disorders: Results From the National Epidemiologic Survey on Alcohol and Related Conditions.[CME]. The Journal of Clinical Psychiatry, 66, 564-574. 
Jrubbs, J. B., Chapman, H., \& Shepherd, K. A. (2019). Post-traumatic stress and gambling related cognitions: Analyses in inpatient and online samples. Addictive Behaviors, 89, 128-135. https://doi.org/10.1016/j.addbeh.2018.09.035

Po Oei, T., Lin, J., \& Raylu, N. (2008). The relationship between gambling cognitions, psychological states, and gambling: A cross-cultural study of Chinese and Caucasians in Australia. Journal of CrossCultural Psychology, 39, 147-161. https://doi.org/10.1177/0022022107312587

Raylu, N., \& Oei, T. P. S. (2004). The Gambling Related Cognitions Scale (GRCS): Development, confirmatory factor validation and psychometric properties. Addiction, 99, 757-769. https://doi.org/10.1111/j.1360-0443.2004.00753.x

Reilly, C., \& Smith, N. (2013). The evolving definition of pathological gambling in the DSM-5. National Center for Responsible Gaming, 1-6.

Ruggiero, K. J., Ben, K. D., Scotti, J. R., \& Rabalais, A. E. (2003). Psychometric properties of the PTSD Checklist - Civilian version. Journal of Traumatic Stress, 16, 495-502.

Scherrer, J. F., Slutske, W. S., Xian, H., Waterman, B., Shah, K. R., Volberg, R., \& Eisen, S. A. (2007). Factors associated with pathological gambling at 10 -year follow-up in a national sample of middleaged men. Addiction, 102, 970-978.

Scherrer, J. F., Xian, H., Kapp, J. M. K., Waterman, B., Shah, K. R., Volberg, R., \& Eisen, S. A. (2007). Association between exposure to childhood and lifetime traumatic events and lifetime pathological gambling in a twin cohort. The Journal of Nervous and Mental Disease, 195, 72-78.

Shapiro, D. N., Chandler, J., \& Mueller, P. A. (2013). Using Mechanical Turk to study clinical populations. Clinical Psychological Science, 1, 213-220.

Smith, D., Harvey, P., Battersby, M., Pols, R., Oakes, J., \& Baigent, M. (2010). Treatment outcomes and predictors of drop out for problem gamblers in south Australia: A cohort study. Australian \& New Zealand Journal of Psychiatry, 44, 911-920. https://doi.org/10.3109/00048674.2010.493502

Taylor, K. M., \& Sharpe, L. (2008). Trauma and posttraumatic stress disorder among homeless adults in Sydney. Australian \& New Zealand Journal of Psychiatry, 42, 206-213. https://doi.org/10.1080/00048670701827218

Toneatto, T., \& Gunaratne, M. (2009). Does the treatment of cognitive distortions improve clinical outcomes for problem gambling? Journal of Contemporary Psychotherapy, 39, 221-229. https://doi.org/10.1007/s10879-009-9119-3

Toneatto, T., \& Pillai, S. (2016). Mood and anxiety disorders are the most prevalent psychiatric disorders among pathological and recovered gamblers. International Journal of Mental Health and Addiction, 14, 217-227. https://doi.org/10.1007/s11469-016-9647-5

Wanner, B., Vitaro, F., Carbonneau, R., \& Tremblay, R. E. (2009). Cross-lagged links among gambling, substance use, and delinquency from midadolescence to young adulthood: Additive and moderating effects of common risk factors. Psychology of Addictive Behaviors, 23, 91-104. https://doi.org/10.1037/a0013182

Westermeyer, J., Canive, J., Garrard, J., Thuras, P., \& Thompson, J. (2005). Lifetime prevalence of pathological gambling among American Indian and Hispanic american veterans. American Journal of Public Health, 95, 860-866. https://doi.org/10.2105/AJPH.2003.023770

Yakovenko, I., Hodgins, D. C., el-Guebaly, N., Casey, D. M., Currie, S. R., Smith, G. J., ... Schopflocher, D. P. (2016). Cognitive distortions predict future gambling involvement. International Gambling Studies, 16, 175-192. https://doi.org/10.1080/14459795.2016.1147592

Young, M. M., \& Wohl, M. J. A. (2009). The Gambling Craving Scale: Psychometric validation and behavioral outcomes. Psychology of Addictive Behaviors, 23, 512-522. https://doi.org/10.1037/a0015043 
This document is a pre-print of the following published manuscript:

Irubbs, J. B., Chapman, H., \& Shepherd, K. A. (2019). Post-traumatic stress and gambling related cognitions: Analyses in inpatient and online samples. Addictive Behaviors, 89, 128-135. https://doi.org/10.1016/j.addbeh.2018.09.035

Table 1

Descriptive statistics for included variables.

\begin{tabular}{|c|c|c|c|c|c|c|c|c|c|c|}
\hline & \multicolumn{5}{|c|}{$\begin{array}{l}\text { Sample 1; Veteran Inpatient Sample } \\
\qquad(N=332)\end{array}$} & \multicolumn{5}{|c|}{$\begin{array}{l}\text { Sample 2; Adult Online Sample } \\
\qquad(N=589)\end{array}$} \\
\hline & Range & $M(S D)$ & Median & Skew & $\alpha$ & Range & $M(S D)$ & Median & Skew & $\alpha$ \\
\hline $\begin{array}{l}\text { Post Traumatic } \\
\text { Stress }\end{array}$ & - & - & - & - & - & $17-85$ & $32.60(15.50)$ & 27.00 & .939 & .952 \\
\hline SOGS & $0-21$ & $\begin{array}{l}14.38 \\
(3.94)\end{array}$ & 15.00 & -1.10 & .952 & $0-21$ & $3.60(3.34)$ & 2.00 & 2.12 & .872 \\
\hline $\begin{array}{l}\text { Gambling } \\
\text { Expectancies }\end{array}$ & $1-7$ & $\begin{array}{l}3.92 \\
(1.61)\end{array}$ & 4.00 & -0.19 & .769 & $1-7$ & $3.27(1.42)$ & 3.25 & 0.14 & .861 \\
\hline $\begin{array}{l}\text { Illusion of } \\
\text { Control }\end{array}$ & $1-7$ & $\begin{array}{c}2.44 \\
(1.36)\end{array}$ & 2.25 & 0.86 & .649 & $1-7$ & $2.19(1.31)$ & 1.75 & 1.09 & .838 \\
\hline $\begin{array}{l}\text { Predictive } \\
\text { Control }\end{array}$ & $1-7$ & $\begin{array}{l}2.91 \\
(1.36)\end{array}$ & 2.67 & 0.47 & .755 & $1-7$ & $3.11(1.27)$ & 3.17 & 0.09 & .814 \\
\hline $\begin{array}{l}\text { Inability to Stop } \\
\text { Gambling }\end{array}$ & $1-7$ & $\begin{array}{c}4.42 \\
(1.36)\end{array}$ & 4.60 & -0.37 & .699 & $1-7$ & $1.78(1.09)$ & 1.20 & 1.73 & .865 \\
\hline $\begin{array}{l}\text { Interpretative } \\
\text { Bias }\end{array}$ & $1-7$ & $\begin{array}{l}4.09 \\
(1.6)\end{array}$ & 4.25 & -0.30 & .736 & $1-7$ & $3.15(1.51)$ & 3.25 & 0.20 & .831 \\
\hline GRCS Total & $1-7$ & $\begin{array}{l}3.55 \\
(1.11)\end{array}$ & 3.55 & .062 & .817 & $1-7$ & $2.70(1.12)$ & 2.55 & .524 & .900 \\
\hline N1 & $20-80$ & $\begin{array}{c}62.03 \\
(11.87)\end{array}$ & 62.00 & -0.40 & - & $1-5$ & $3.09(1.13)$ & 3.25 & -0.13 & .848 \\
\hline $\mathrm{N} 2$ & $20-80$ & $\begin{array}{c}60.68 \\
(12.78)\end{array}$ & 61.00 & -0.00 & - & $1-5$ & 2.77 (1.09) & 2.75 & 0.11 & .867 \\
\hline N3 & $20-80$ & $\begin{array}{c}70.41 \\
(12.23)\end{array}$ & 72.00 & -0.96 & - & $1-5$ & $2.61(1.25)$ & 2.50 & 0.28 & .915 \\
\hline N4 & $20-80$ & $\begin{array}{c}61.99 \\
(11.49)\end{array}$ & 61.00 & 0.15 & - & $1-5$ & $2.74(0.99)$ & 2.75 & 0.21 & .770 \\
\hline N5 & $20-80$ & $\begin{array}{c}65.09 \\
(10.38)\end{array}$ & 66.00 & -0.02 & - & $1-5$ & $2.96(1.00)$ & 3.00 & -0.07 & .757 \\
\hline N6 & $20-80$ & $\begin{array}{c}67.78 \\
(15.01) \\
\end{array}$ & 68.00 & 0.15 & - & $1-5$ & $2.49(0.99)$ & 2.50 & 0.46 & .822 \\
\hline $\begin{array}{l}{ }^{¥} \text { Sample 1, PTSS } \\
\text { Abbreviations: Sa } \\
\text { N1= Anxiety, An } \\
\text { Immoderation; N }\end{array}$ & $\begin{array}{l}\text { ts asses } \\
\text { le } 1(\mathrm{~N} \\
\text { ty; N2= } \\
\text { Julnera }\end{array}$ & $\begin{array}{l}\text { via the pr } \\
\text { PI-R), Se } \\
\text { rry Hostil } \\
\text { y, Vulner }\end{array}$ & $\begin{array}{l}\text { ce or abs } \\
2 \text { (NEO } \\
\text { Anger; } N \\
\text { ty }\end{array}$ & $\begin{array}{l}\text { a PTS } \\
\text { 20) } \\
\text { ession, }\end{array}$ & nos & Sam & $\begin{array}{l}\text { TSS was as } \\
\text { ciousness, }\end{array}$ & $\begin{array}{l}\text { via } \\
\text { onsci }\end{array}$ & on th & C. \\
\hline
\end{tabular}


Table 2

Sample 1, Independent T-Test comparison of participants with a PTSD diagnosis to those without a PTSD diagnosis.

\begin{tabular}{|c|c|c|c|c|c|c|c|}
\hline \multicolumn{8}{|c|}{ PTSD Status } \\
\hline & $\begin{array}{c}\text { No PTSD } \\
(n=189) \\
M(S D)\end{array}$ & $\begin{array}{c}\text { PTSD } \\
(n=140) \\
M(S D) \\
\end{array}$ & $\begin{array}{c}\text { Mean } \\
\text { Difference }\end{array}$ & $t$ & $d f$ & $p$ & Cohen's $d$ \\
\hline $\begin{array}{l}\text { South Oaks } \\
\text { Gambling Screen }\end{array}$ & $14.5(4.16)$ & $14.22(3.66)$ & 0.28 & 0.64 & 327 & .524 & 0.07 \\
\hline $\begin{array}{l}\text { Gambling } \\
\text { Expectancies }\end{array}$ & $3.64(1.63)$ & $4.30(1.52)$ & -0.66 & -3.72 & 326 & .001 & -0.42 \\
\hline Illusion of Control & $2.25(1.31)$ & $2.70(1.38)$ & -0.44 & -2.96 & 326 & .003 & -0.33 \\
\hline Predictive Control & $2.72(1.33)$ & $3.18(1.36)$ & -0.46 & -3.09 & 326 & .002 & -0.35 \\
\hline $\begin{array}{l}\text { Inability to Stop } \\
\text { Gambling }\end{array}$ & $4.28(1.45)$ & $4.62(1.20)$ & -0.34 & -2.27 & 326 & .024 & -0.25 \\
\hline Interpretative Bias & $3.88(1.66)$ & $4.36(1.47)$ & -0.48 & -2.70 & 326 & .007 & -0.30 \\
\hline GRCS Total & $3.35(1.11)$ & $3.83(1.07)$ & -0.47 & -3.91 & 326 & $<.001$ & -0.44 \\
\hline
\end{tabular}


Irubbs, J. B., Chapman, H., \& Shepherd, K. A. (2019). Post-traumatic stress and gambling related cognitions: Analyses in inpatient and online samples. Addictive Behaviors, 89, 128-135. https://doi.org/10.1016/j.addbeh.2018.09.035

Table 3

Pearson correlations for included variables.

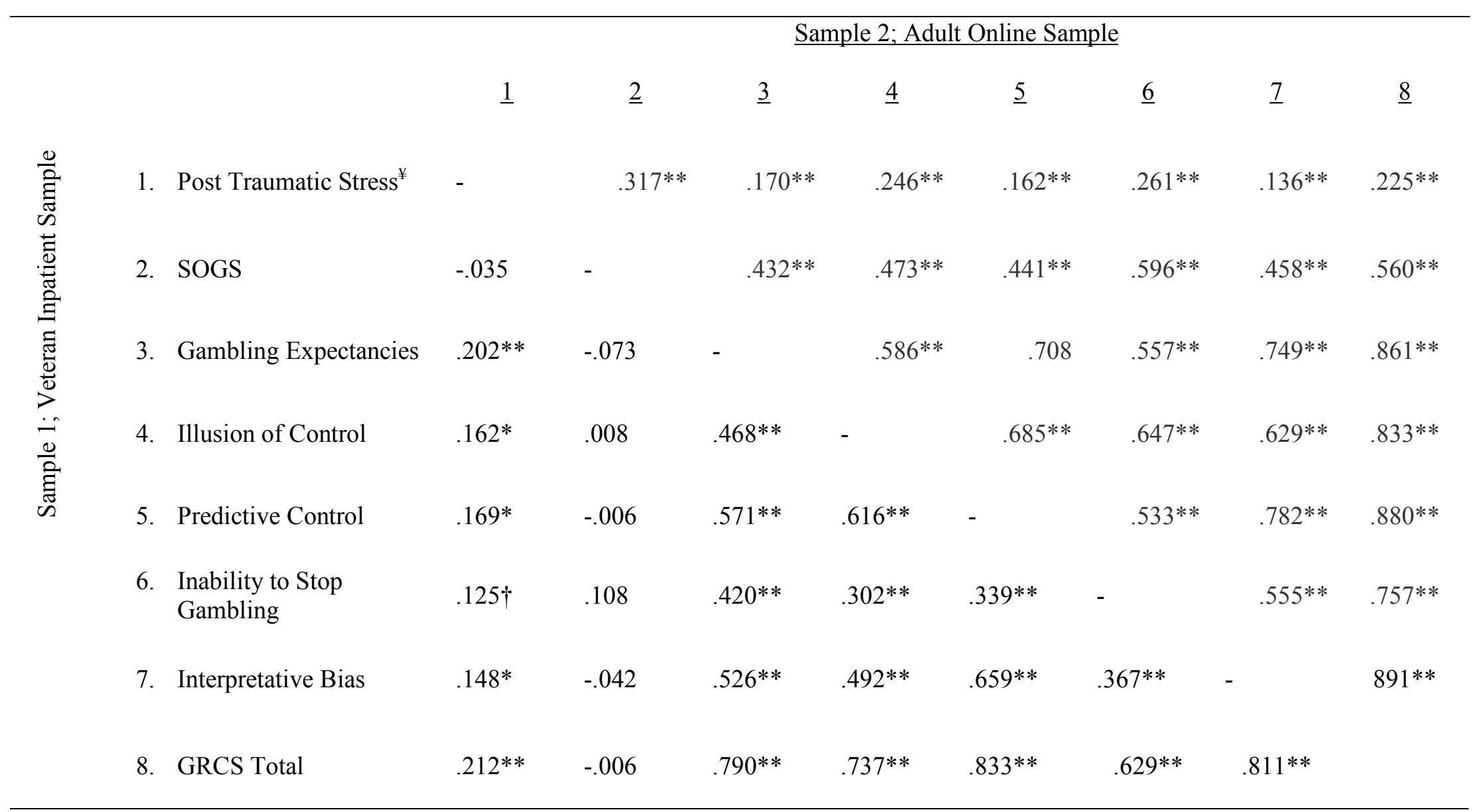

$\dagger p<.05 ; * p<.01 ; * * p<.001$

${ }^{¥}$ Sample 1, PTSS was assessed via the presence or absence of a PTSD diagnosis. Sample 2, PTSS was assessed via scores on the PCL-C. 
This document is a pre-print of the following published manuscript:

Irubbs, J. B., Chapman, H., \& Shepherd, K. A. (2019). Post-traumatic stress and gambling related cognitions: Analyses in inpatient and online samples. Addictive Behaviors, 89, 128-135. https://doi.org/10.1016/j.addbeh.2018.09.035

Table 4

Sample 1: Two-Step, Hierarchical Regression Predicting Gambling Related Cognitions

\begin{tabular}{|c|c|c|c|c|c|c|c|c|c|c|c|c|}
\hline & \multicolumn{2}{|c|}{$\begin{array}{l}\text { Gambling } \\
\text { Expectancies }\end{array}$} & \multicolumn{2}{|c|}{ Illusion of Control } & \multicolumn{2}{|c|}{ Predictive Control } & \multicolumn{2}{|c|}{$\begin{array}{l}\text { Inability to Stop } \\
\text { Gambling }\end{array}$} & \multicolumn{2}{|c|}{$\begin{array}{l}\text { Interpretative } \\
\text { Bias }\end{array}$} & \multicolumn{2}{|c|}{$\begin{array}{l}\text { GRCS } \\
\text { Total }\end{array}$} \\
\hline & Step 1 & Step 2 & Step 1 & Step 2 & Step 1 & Step 2 & Step 1 & Step 2 & Step 1 & Step 2 & Step 1 & Step 2 \\
\hline SOGS & -.108 & -.098 & -.024 & -.014 & -.050 & -.040 & .057 & .062 & -.063 & -.054 & -.055 & -.043 \\
\hline N1 & -.043 & -.084 & $-.233 * *$ & $-.274 * *$ & $-.194 *$ & $-.231 * *$ & .008 & -.008 & -.166 & -.201 & $-.164 \dagger$ & $-.210^{*}$ \\
\hline $\mathrm{N} 2$ & -.009 & -.015 & .036 & .029 & .071 & .065 & -.012 & -.015 & .126 & .120 & .058 & .050 \\
\hline N3 & -.088 & -.084 & .145 & .150 & .152 & .156 & .084 & .086 & .039 & .043 & .079 & .085 \\
\hline N4 & .022 & .050 & -.003 & .025 & -.038 & -.012 & .056 & .068 & .050 & .075 & .025 & .057 \\
\hline N5 & $.155^{*}$ & $.155^{*}$ & -.022 & -.021 & .071 & .071 & $.141^{*}$ & $.141^{*}$ & .179 & .180 & $.146 \dagger$ & $.147 \dagger$ \\
\hline N6 & .135 & .112 & $.185^{*}$ & $.161^{*}$ & $.159 *$ & .137 & $.158^{*}$ & $.149 *$ & -.026 & -.046 & $.157 \dagger$ & .13 \\
\hline $\begin{array}{l}\text { Post } \\
\text { Traumatic } \\
\text { Stress }\end{array}$ & & $.176^{* *}$ & & $.180 * *$ & & $.162 * *$ & & .072 & & $.155^{* *}$ & & $.200 * *$ \\
\hline $\begin{array}{r}R 2 \\
\Delta R 2 \\
f 2 \text { for } \Delta R 2 \\
\mathrm{~F} \text { for } \Delta R 2 \\
\end{array}$ & $\begin{array}{l}.043 \\
\\
.045 \\
1.87 \\
\end{array}$ & $\begin{array}{l}.072 \\
.029 \\
.030 \\
8.85^{* *} \\
\end{array}$ & $\begin{array}{l}.050 \\
.053 \\
2.20 * \\
\end{array}$ & $\begin{array}{l}.080 \\
.030 \\
.031 \\
9.34 * * \\
\end{array}$ & $\begin{array}{l}.063 \\
.067 \\
2.80^{* *} \\
\end{array}$ & $\begin{array}{l}.088 \\
.025 \\
.026 \\
7.62 * * \\
\end{array}$ & $\begin{array}{l}.133 \\
.153 \\
6.35^{* *} \\
\end{array}$ & $\begin{array}{l}.138 \\
.005 \\
.005 \\
1.58 \\
\end{array}$ & $\begin{array}{l}.060 \\
.064 \\
2.62 * \\
\end{array}$ & $\begin{array}{l}.082 \\
.022 \\
.022 \\
6.94 * * \\
\end{array}$ & $\begin{array}{l}.081 \\
.088 \\
3.65^{* *} \\
\end{array}$ & $\begin{array}{l}.118 \\
.037 \\
.038 \\
12.02 * *\end{array}$ \\
\hline
\end{tabular}

$\dagger p<.05 ; * p<.01 ; * * p<.001$

Abbreviations: N1= Anxiety; N2=Angry Hostility; N3=Depression; N4=Self-Consciousness; N5=Impulsivity; N6=Vulnerability 
This document is a pre-print of the following published manuscript:

Irubbs, J. B., Chapman, H., \& Shepherd, K. A. (2019). Post-traumatic stress and gambling related cognitions: Analyses in inpatient and online samples. Addictive Behaviors, 89, 128-135. https://doi.org/10.1016/j.addbeh.2018.09.035

Table 5

Sample 1: Two-Step, Hierarchical Regression Predicting Gambling Related Cognitions

\begin{tabular}{|c|c|c|c|c|c|c|c|c|c|c|c|c|}
\hline & \multicolumn{2}{|c|}{$\begin{array}{c}\text { Gambling } \\
\text { Expectancies }\end{array}$} & \multicolumn{2}{|c|}{ Illusion of Control } & \multicolumn{2}{|c|}{ Predictive Control } & \multicolumn{2}{|c|}{$\begin{array}{l}\text { Inability to Stop } \\
\text { Gambling }\end{array}$} & \multicolumn{2}{|c|}{ Interpretative Bias } & \multicolumn{2}{|c|}{$\begin{array}{l}\text { GRCS } \\
\text { Total }\end{array}$} \\
\hline & Step 1 & Step 2 & Step 1 & Step 2 & Step 1 & Step 2 & Step 1 & Step 2 & Step 1 & Step 2 & Step 1 & Step 2 \\
\hline SOGS & $.417 * *$ & $.392 * *$ & $.468 * *$ & $.414 * *$ & $.426 * *$ & $.392 * *$ & $.594 * *$ & $.562 * *$ & $.460 * *$ & $.435 * *$ & $.568 * *$ & $.531 * *$ \\
\hline N1 & .014 & .000 & -.093 & $-.124 *$ & -.057 & -.077 & $-.155^{* *}$ & $-.173 * *$ & -.030 & -.045 & -.084 & -.099 \\
\hline $\mathrm{N} 2$ & -.049 & -.056 & .034 & .018 & .041 & .031 & .024 & .015 & -.015 & -.022 & .029 & .019 \\
\hline N3 & -.059 & -.091 & -.089 & $-.162 * *$ & $-.141 *$ & $-.186^{* *}$ & -.026 & -.069 & $-.116^{*}$ & $-.149 *$ & -.089 & $-.140 \dagger$ \\
\hline N4 & .055 & .064 & .010 & .030 & .032 & .045 & $.116^{*}$ & $.128 \dagger$ & .099 & $.109 *$ & .073 & .087 \\
\hline N5 & -.007 & -.011 & -.012 & -.021 & .032 & .026 & -.069 & -.075 & -.008 & -.012 & -.019 & -.022 \\
\hline N6 & -.040 & -.054 & & .062 & .001 & -.019 & .113 & $.102 \dagger$ & -.048 & -.063 & .019 & -.002 \\
\hline $\begin{array}{l}\text { Post } \\
\text { Traumatic } \\
\text { Stress }\end{array}$ & & $.097 * *$ & & $.219 * *$ & & $.136^{* *}$ & & $.127 *$ & & $.101 *$ & & $.147 * *$ \\
\hline $\begin{array}{r}R 2 \\
\Delta R 2\end{array}$ & .191 & $\begin{array}{l}.198 \\
.007\end{array}$ & .235 & $\begin{array}{l}.261 \\
.027\end{array}$ & .211 & $\begin{array}{l}.220 \\
.009\end{array}$ & .376 & $\begin{array}{l}.385 \\
.009\end{array}$ & .225 & $\begin{array}{l}.229 \\
.004\end{array}$ & .324 & $\begin{array}{l}.337 \\
.013\end{array}$ \\
\hline $\begin{array}{r}f 2 \text { for } \Delta R 2 \\
\mathrm{~F} \text { for } \Delta R 2\end{array}$ & $\begin{array}{l}.236 \\
18.0^{* *}\end{array}$ & $\begin{array}{l}.007 \\
4.5 \dagger \\
\end{array}$ & $\begin{array}{l}.307 \\
24.8 * *\end{array}$ & $\begin{array}{l}.028 \\
20.4^{* *}\end{array}$ & $\begin{array}{l}.267 \\
21.6 * *\end{array}$ & $\begin{array}{l}.009 \\
6.8^{*} \\
\end{array}$ & $\begin{array}{l}.603 \\
48.9^{* *}\end{array}$ & $\begin{array}{l}.009 \\
8.2^{*}\end{array}$ & $\begin{array}{l}.290 \\
23.75^{* *} \\
\end{array}$ & $\begin{array}{l}.004 \\
3.1 \\
\end{array}$ & $\begin{array}{l}.479 \\
38.83^{* *} \\
\end{array}$ & $\begin{array}{l}.013 \\
11.49 * *\end{array}$ \\
\hline
\end{tabular}

$\dagger p<.05 ; * p<.01 ; * * p<.001$

Abbreviations: N1=Anxiety; N2= Anger; N3=Depression; N4= Self-Consciousness; N5=Immoderation; N6=Vulnerability 